\title{
NOTAS SOBRE O PENSAMENTO DE BENTO PRADO JR.: AS CIÊNCIAS COGNITIVAS E A IPSEIDADE
}

\author{
Eduardo Toshio Kobori ${ }^{1}$ \\ Rita Ferreira da Silva ${ }^{2}$ \\ Fábio Ságula de Oliveira ${ }^{3}$
}

\begin{abstract}
Resumo: Neste ensaio, pretendemos discutir a obra póstuma de Bento Prado Jr.: o Ipseitas. Mais especificamente, o capítulo em que o autor trata das ciências cognitivas e analisa o livro de Rodolfo Llinás, intitulado I of the Vortex: From neurons to Self. A crítica do filósofo brasileiro poderia ser dividida em duas: a primeira discorre sobre uma espécie de retorno ao naturalismo, evidenciado em alguns estudos da área das ciências cognitivas; a segunda se concentra na análise de alguns trechos da obra citada anteriormente, no que concerne a sua principal aspiraçáo: deduzir a consciência a um biologismo neuronal. Bento Prado Jr. neste capítulo argumenta a respeito dos desdobramentos decorrentes da problemática proposição de Llinás, cuja discussão gira em torno do engendramento da subjetividade.
\end{abstract}

Palavras-chave: Bento Prado Jr; Ipseitas, subjetividade, ciências cognitivas.

\section{NOTES ON THE THOUGHT OF BENTO PRADO JR :: COGNITIVE SCIENCES AND IPSEITY}

\begin{abstract}
In this essay, we intend to discuss the posthumous work of Bento Prado Jr.: the Ipseitas. More specifically, the chapter in which the author deals with the cognitive sciences and analyzes the book of Rodolfo Llinás, titled I of the Vortex: From neurons to Self. The criticism of the Brazilian philosopher could be divided into two: first discusses a kind of return to naturalism, evidenced in some studies in the area of cognitive sciences; second focuses on the analysis of some passages of the aforementioned work, in what concerns its main aspiration: to deduce consciousness from a neuronal biologism. Bento Prado Jr. in this chapter argues about the unfolding arising from Llinás's problematic proposition, whose discussion revolves around the engendering of subjectivity.
\end{abstract}

Keywords: Bento Prado Jr; Ipseitas, subjectivity, cognitive science.

1 Psicólogo, mestre e doutorando em Filosofia pela UNIFESP, professor do curso de psicologia da Uni-FIO.

2 Psicóloga (UNI-FIO), especialista em Psicopedagogia (UENP).

3 Psicólogo, doutor em Educação (UNESP), coordenador do curso de Psicologia da UNI-FIO.

-- Artigo Recebido em 18/04/2019. ACEIto em 28/06/2019. --

Signos, Lajeado, ano 40, n. 1, p. 150-157, 2019. ISSN 1983-0378 


\section{Algumas consideraçóes iniciais}

Publicado postumamente, o Ipseitas de Bento Prado Jr. deveria ser o primeiro livro de uma trilogia, cujo título seria "A ipseidade e suas formas de expressão". Os outros dois volumes não foram esboçados, apenas intitulados como: "Actio" e "Comtemplatio". Estes volumes pretendiam dar continuidade ao projeto tratando da ipseidade e suas manifestações nas obras filosóficas, literárias e no discurso político.

No entanto, a obra publicada e editada por Vladimir Safatle, e que trataremos nesse ensaio é o Ipseitas, especificamente, o primeiro capítulo da segunda parte: O lugar do cogito na filosofia analitica e nas "ieencias cognitivas". Neste capítulo, Bento Prado levanta duas questões relevantes à sua proposta de discussão da ipseidade no contemporâneo, isto é, naquele final do século XX, mas que certamente se arrastam até a atualidade. A primeira delas consiste no apontamento de um movimento ocorrido no interior das cognitive sciences, cuja produção científica resulta numa espécie de "saudosismo retrógrado" (BENTO PRADO, 2017, p. 137), ou seja, uma espécie de repetição ou retorno a uma forma de pensamento oriunda do comtismo e de influência naturalista. A segunda concentra-se na crítica aos argumentos que Rodolfo R. Llinás tenta defender em, I of the vortex: From neurons to Self, obra cujo objetivo visava à dedução neurológica da subjetividade e do problema da consciência e seus estados. É sobre estas duas questões que nos debruçaremos nesse texto, partindo da crítica de Bento Prado ao status quo do pensamento científico e seus desdobramentos, bem como à problematização do argumento naturalista e biologizante da questão da ipseidade.

\section{Dos neurônios ao Eu ou do naturalismo ao erro de categoria?}

Bento Prado Jr inicia seu capítulo com a denúncia de um paradoxo de nossa atualidade em decorrência das novas tecnologias e da economia. Para o autor, ainda que haja um avanço técnico-científico e econômico, ao se examinar a produção das cognitive sciences pode-se perceber um retrocesso, pelo menos na maneira como tais pesquisas se apresentam: com a atmosfera do naturalismo do século XIX. Isto, pois, a tendência de investigação das ciências cognitivas reside no substrato biológico, resultando em um reducionismo do ser às atividades cerebrais.

Ademais, o paradoxo residiria, segundo o filósofo brasileiro, no seguinte: "tudo se passa como se boa parte dos pensadores contemporâneos ignorassem todas as grandes obras do século XX" (BENTO PRADO, 2017, p. 135). Tais autores ignoram toda discussão filosófica dos grandes pensadores a respeito da consciência porque estão concentrados na explicação causal do funcionamento mental somente na parte biológica de seus mecanismos. Esse retorno referido por Bento Prado é exemplificado com uma frase de 150 anos atrás, de Büchner, que dizia: "o cérebro seria uma espécie de glândula e o pensamento sua secreção"(Idem). Ora, uma asserção desse tipo resulta em um monismo reducionista que aspira a um positivismo dito "científico", o que atualmente é reconhecido como valor de verdade. 
As ciências cognitivas chegam atrasadas ao nosso tempo, por isso são recentes, elas dependiam do avanço tecnológico para que sua metodologia pudesse incidir sobre seu objeto de maneira fidedigna - mas nem sempre razoável. No entanto, esse fato não abona a recusa de um campo que discute há séculos o tema da subjetividade.

Bento Prado Jr. endossa seu argumento citando um artigo de Peter Burke publicado em 11 de julho de 2004. Nele, o historiador se apoia na obra de outros dois autores: Carlo Fumian em sua obra Verso una societá planetária (2003); e Christopher Bayly em The birth of modern world (2004). Essas duas obras tratam das transformações ocorridas em consequência do processo de globalização, mas o que interessa a Bento Prado Jr. é a conclusão a que chegam os dois historiadores sobre o período de 1870-1914, cujas transformações são repetidas estruturalmente na virada do século XX. Isto, podemos perceber ao comparar a tendência ao pensamento de Augusto Comte no fim do século XIX com a nossa mais recente virada do século XX e o surgimento das cognitive sciences, tal como nos apresenta Bento Prado:

No campo da filosofia observa-se, no ciclo mais curto (1870-1914), a disseminação mundial do positivismo que chegaria até o Brasil, no século XIX, como hoje aqui aportam as chamadas cognitive sciences, animadas pelo mesmo cientificismo do pensamento de Augusto Comte. (BENTO PRADO, 2017, p. 137).

É nessa atmosfera de cientificismo positivo que as ciências cognitivas pressupõem, de maneira ambiciosa, a elucidação do funcionamento mental e seus desdobramentos, tal como um processo de uma lógica naturalista. Este posicionamento se torna problemático, na medida em que a própria objetividade a que aspiram essas áreas científicas não comporta a complexidade de seu objeto.

Dito isto, Bento Prado Jr. pode então iniciar sua análise ao alvo principal de seu capítulo, a crítica à obra do professor da Universidade de Nova York, Rodolfo R. Llinás, I of the Vortex: from neurons to Self. Segundo o filósofo brasileiro, no primeiro capítulo, Llinás declara a ousadia de seu projeto, cuja intenção designa-se a passar da fisiologia da célula para o nível sistêmico da ação e da representação. Bento sugere ignorarmos essa questão inicial, de um dogmatismo implícito que supõe duas "metafísicas" para os problemas da práxis e da noésis: dualismo ou monismo. Nosso autor prefere apontar esta afirmação de Llinás: "from my monist's perspective, the brain and the mind are inseparable events" (LLINÁS, 2001, p. 1). Nesta declaração aponta Bento, não seria necessária a escolha especulativa de uma posição monista, uma vez que seria absurdo afirmar que mente e cérebro são eventos inseparáveis. Mas, continua nosso autor, mais interessante que isso, o neurocientista recusa o modelo mecanicista/reflexológico (input-output) e insiste na relevância do contexto da cognição e da ação para que a interação do cérebro com os estímulos externos logre êxito. Embora Bento não aprofunde esse comentário, o texto de Llinás explicita que o esquema de estímulo-resposta não funciona de maneira tão direta, tal como no exemplo do ato de coçar um prurido. Contudo, antes da resposta ao estímulo, ou seja, antes da ação, há a construção de uma imagem interna, ou imagem 
sensório-motora. Ela não se limita a imagem visual, mas quando construída, fornece uma localização viso-espacial, no caso do exemplo do prurido, não conseguimos enxergar, mas a imagem sensório-motora coordena a ação no local do corpo onde o prurido se encontra.

Dessa forma, o contexto será importante para compreender o motivo da ação ou da falta da ação, não haverá ação adequada se o contexto não o permitir, recusando assim o mero automatismo da resposta do tipo reflexo.

Esta construção da imagem sensório-motora, com a recusa do sistema arco-reflexo, configura-se, tal como nos parece, como uma espécie de mediação da consciência, entre o exterior e o interior. Aliado a isto, Bento Prado Jr., nos chama a atenção para essa relação sistêmica do ponto de partida do neurologista, que pressupõe algo como uma "ipseidade larvar, ou seja, uma referência a si mesmo presente no nível mais elementar do funcionamento neuronal" (BENTO PRADO, 2017, p. 137).

O trecho a que o autor brasileiro se refere, postula o cérebro como uma entidade viva e que engendra uma atividade elétrica bem definida. Para Bento essa perspectiva se aproxima à neurologia da primeira metade do século XX e de um "integracionismo" de inspiração gestáltica, utilizada por autores como MerleauPonty e Cassirer, filósofos pouco monistas, contradizendo a posição declarada no caput do capítulo 1. Esses aspectos, segundo o filósofo brasileiro, sugerem uma criptofenomenologia da intencionalidade larvar do sistema neuronal, isto é, há uma fenomenologia inserida na teoria que Llinás tenta formular, porém ele próprio não o sabe.

Além disso, o professor da Universidade de Nova York, ao elencar as diferentes formas de atividade cerebral, dentre elas, o sono profundo, o sonho e o sonho lúcido, apresenta "uma teoria criptokantiana dos níveis sucessivos da intuição sensível, da imaginação transcendental produtiva e do próprio entendimento" (BENTO PRADO, 2017, p. 139). Esse procedimento, de dedução do estatuto do sujeito por meio dos fatos da ciência da natureza e da reflexividade do neurônio está inscrita em sua própria característica, em sua essência, por assim dizer, como livre da atuação exterior. O pesquisador das neurociências parece mesmo mais propenso ao lado desse aspecto não relacionado ao mundo exterior quando declara:

The processes that generate such states as thinking, consciousness, and dreaming are foreign to us, I fancy, because they always seem to be generated with no apparent relation to the external world. (LLINÁS, 2001, p.4)

A partir desse ponto, Llinás introduz uma ideia que Bento Prado chamará de "insustentável". O neurocientista leva às últimas consequências o aspecto interior do cérebro, sem relação com o mundo exterior, ao abordar a questão da maneira mais física - concreta - possível. A fim de defender seu argumento, ele se apoia em uma obra de Stephen J. Gould, publicada em 1990 e intitulada: "Unity of Organic Design: from Goethe and Geoffrey Chaucer to Homology of Homeotic Complexes in Arthropods and vertebrates". Nela, Llinás encontra a ideia de que somos crustáceos virados ao avesso, por meio da evolução, ou seja, o exoesqueleto tornou-se endoesqueleto. 
Se por um lado os crustáceos com seu exoesqueleto não podem ter acesso aos seus movimentos, pois estão encerrados dentro da estrutura esquelética. Por outro lado, os seres humanos, que possuem estrutura endoesquelética desde o nascimento, possuem acesso aos seus movimentos e, com isto, adquirem a noção do funcionamento de suas articulações. No caso do cérebro, ele ainda está encerrado dentro da caixa craniana, tal como um exoesqueleto, e por conta disso, existiria a dificuldade em acessar e compreender o seu funcionamento neuronal. Nas palavras do autor:

If we could observe or feel the brain at work, it would be immediately obvious that neuronal function is as related to how we see, interpret, and react, as muscle contractions are related to the movements we make. (Idem).

Antes de retomarmos a argumentação de Bento Prado, poderíamos questionar esse posicionamento de Llinás no seguinte sentido: será que se de fato tivéssemos acesso à massa cinzenta de maneira externa ao crânio, teríamos essa percepção a qual nos diz o autor? Seu argumento compara a percepção do funcionamento neuronal com a percepção do movimento do corpo, dos músculos e dos tendões, contudo, nenhum ser humano sente o comando sináptico sendo enviado ou trafegando entre os tendões, mesmo que seja em uma estrutura endoesquelética. Ainda, pensar nesses termos seria de fato útil? Uma vez que não temos acesso, nem talvez nunca tenhamos o cérebro fora da caixa craniana. De qualquer modo, a proposição de Llinás é fortemente especulativa, sem uma argumentação razoável.

Essa argumentação problemática de Llinás poderia ser efeito do que aponta Bento, ao recorrer a Wittgenstein, sobre a irredutibilidade da gramática da psicologia à da análise do funcionamento do cérebro. Isto quer dizer que se trata de dois jogos de linguagem diferentes, ainda que pertençam a uma área em comum, suas gramáticas e jogos de linguagem são diferentes. Mas nosso autor não prossegue, retornará ao Wittgenstein mais adiante.

Não obstante, Bento Prado se indaga a respeito das consequências da proposição especulativa de Llinás, "que podemos imaginar - ou pensar - que ocorreria se, sem o exoesqueleto craniano, tivéssemos acesso imediato aos processos neuronais?” (BENTO PRADO, 2017, p. 142). O próprio autor responde na sequência, afirmando que teríamos a percepção ou consciência imediata intencional de novos processos físicos. Isto significa dizer que tal como sabemos, sentimos e controlamos os movimentos do braço, por exemplo, da mesma forma, ocorreria com estes novos processos físicos. O filósofo brasileiro nos fornece um exemplo extraído da tese de doutoramento de sua esposa, Lúcia Prado, sobre o problema da orientação das saúvas. A partir desse trabalho, pode-se perceber que não é possível inferir, por meio da inspeção dos processos neuronais, o que a saúva está vendo, qual objeto, a que distância, ou outras características. Apenas podese averiguar seu comportamento diante de alguns objetos e assim, confirmar sua percepção. Contudo, nos avisa Bento, essas observações críticas vão ao encontro de outras formulações filosóficas, como a de Sir Karl Popper que propõe três níveis que jamais podem ser confundidos: o mundo da realidade física, o do pensamento 
humano e o dos conteúdos de pensamento objetivados na linguagem. A obra que fundamenta o comentário de Bento chama-se Mente, cérebro, cognição, de João de Fernandes Teixeira. A questão que circunscreve tanto o comentário de Bento quanto o de João de Fernandes Teixeira designa-se pelo que este último chama de hiato intransponível entre cérebro e estados subjetivos. Em outras palavras, trata-se da dificuldade de encontrar o elo que constitua um nexo entre os eventos físicos neuronais que ocorrem no cérebro - ou a tempestade elétrica de Llinás e a própria experiência dos estados da consciência ou dos pensamentos. Bento Prado Jr. nos diria: "Se eu anunciar quaisquer proposições (por exemplo: $2+2$ $=4 ; 2+2=1000$; dois mais dois esbórnia amarelo-x-girafa), sempre hão de lhes corresponder processos neuronais" (BENTO PRADO, 2017, p. 143). Isto significa que é possível perceber alguma atividade no cérebro nessas proposições, no entanto, seria impossível discernir o que é verdadeiro do que é falso, apenas confirma-se que houve uma operação, mas sem conseguir discernir sua qualidade.

Outro exemplo, dessa vez de João de Fernandes Teixeira, consiste no eletroencefalograma, cujo exame permite verificar se uma pessoa, enquanto dorme, está sonhando ou não. Todavia, não é possível identificar com o que ela sonha, ou seja, o conteúdo do sonho não é aferível por meio desse instrumento. Daí que podemos confirmar a correlação entre o evento físico e o evento subjetivo, mas esses dois tipos de séries ainda permanecem distantes de se corresponderem de maneira mais direta.

Retomando nosso capítulo sobre as ciências cognitivas, Bento Prado dá um salto até o capítulo 6 da obra de Llinás. Nele, o filósofo brasileiro encontra uma conclusão que aponta justamente para uma contradição do que o neurocientista havia defendido até então. Nas palavras do autor de I of the Vortex:

The implications of this proposal are of some consequence, for if consciousness is a product of thalamocortical activity, as it appears to be, it is the dialogue between the thalamus and the cortex that generates subjectivity in humans and in higher vertebrates. (LLINÁS, 2001, p. 131).

A afirmação acima indica que seria o diálogo entre o tálamo e o córtex que engendraria a subjetividade. Ao que Bento replica, questionando novamente, a possibilidade de aferição da subjetividade a partir de alguma atividade neuronal observada por meio de técnicas e métodos específicos. No entanto, não é possível perceber, em seu conteúdo, o que é verdadeiro ou o que é falso, naquela observação do impulso elétrico, ou do diálogo entre tálamo e córtex, por exemplo. Isto, pois, segundo nosso autor, "é preciso que alguém perceba as conexões entre a percepção e seu substrato.” (BENTO PRADO, 2017, p. 145).

$\mathrm{Na}$ citação anterior, nos parece que o argumento da intransponibilidade retorna exigindo um testemunho que ateste a percepção e o seu substrato físico correspondente, o que demandaria na visão de Llinás, apontada por Bento Prado, que são os próprios neurônios "através dos estados secundários de consciência (do Self), percebem a si mesmos e enunciam proposições não só significativas como também verdadeiras, a respeito de seu próprio funcionamento" (Idem). E, 
neste movimento, cuja atividade engendra a subjetividade produzida pelo próprio neurônio, há uma inversão de posicionamento: de um materialismo reducionista para um idealismo absoluto.

Uma vez que Llinás defendia os processos neuronais como a causa dos estados de consciência, resultando assim numa metafísica naturalista e objetivista, e, contudo, sua argumentação volta-se contra si mesmo quando postula essa transparência onde os neurônios produzem sua própria atividade e percepção de si mesmos, se transformando em um idealismo. A crítica de Bento Prado nesse ponto refere-se ao contorno do "mistério da consciência", efetuado pelo neurologista, cuja resolução para o problema, além de ser simplista, tenta deduzir biologicamente algo que já estaria presente como inerente à sua natureza.

Por fim, Bento Prado conclui a análise da obra de Rodolfo Llinás, com a constatação de que a gênese da ipseidade do sujeito se encontra inserida na própria célula neuronal, que pensa a si mesma. A resolução mágica que propõe o neurologista para o problema da subjetividade pode ser ilustrada tal como nosso autor, de maneira irônica, cita a frase do velho testamento: "Fiat lux, e a luz foi feita” (BENTO PRADO, 2017, p. 146).

Ademais, nos lembra o filósofo brasileiro, o essencial hiato kantiano entre a questão "quid facti" e a questão "quid juris" fora negligenciado. Isto é, onde estão as análises lógicas da produção de conhecimento? As questões de fato estão aí, com suas respostas sejam elas mirabolantes ou não, mas, e quanto às questões de validade ou de justificação? Em outras palavras, Llinás não conseguiria passar suas asserções por um crivo deste tipo, pois como fora demonstrado anteriormente, o neurologista tropeça na contradição de seus enunciados e na formulação da gênese da subjetividade, cujo contorno desvia do enfrentamento do problema.

Bento Prado Jr., termina o ensaio voltando ao questionamento inicial do capítulo, cuja preocupação gira em torno do status quo do distorcido pensamento científico: "nessa aurora do século XXI, estamos em plena metade do século XIX." (BENTO PRADO, 2017, p. 146).

\section{Consideraçóes finais}

O ensaio ao qual nos debruçamos nesse texto, O lugar do cogito na filosofia analítica e nas "ciências cognitivas", segue a proposta do projeto do Ipseitas na medida em que - apesar de não operar uma releitura dos filósofos que se ocuparam do tema da ipseidade -, constitui-se como uma análise crítica de uma nova produção científica que aspira ao desvendamento do enigma da consciência, tal qual toda a tradição filosófica com que trabalha Bento Prado.

Não seria necessário e nem útil repetir tudo que foi dito nas páginas anteriores, no entanto, cabe salientar nessa conclusão que o texto de Bento Prado denuncia erros graves de argumentação, não apenas na obra de Rodolfo Llinás, mas a todo o campo das neurociências, e de outras áreas científicas que almejam uma cientificidade amparada pela metodologia das hard sciences. Os equívocos 
resultantes de tais produções podem conduzir a graves mal-entendidos, tal como o reducionismo em que opera Llinás. Este movimento, nas palavras do autor, retrógrado, faz com que o positivismo carregado nas cognitive sciences se transforme em um naturalismo onde se ambiciona responder às questões deduzindo-as ao corpo biológico, somente. O problema reside no fato de que Llinás gira em torno de si mesmo sem sair do lugar, para, por fim propor uma saída que não soluciona o que pretendia.

Nesse sentido, Bento Prado Jr. nos lembra do retorno a Kant, e de uma resolução mais razoável. Ao distinguir o sujeito transcendental e o sujeito empírico, haveria possibilidade de conciliação entre a apercepção pura e o realismo empírico, entendidos como percepção de si mesmo e a própria materialidade do mundo exterior, respectivamente. Isto, sem prejuízo, segundo o filósofo brasileiro, para a autonomia do conhecimento científico do mundo exterior. Esta seria, de acordo com a opinião do nosso autor, uma "quase perspectiva de superação da alternativa naturalismo/idealismo" (Idem). Com efeito, uma resolução mais elaborada e coerente do que a de Rodolfo Llinás, que em vez de ultrapassar o dualismo, confunde-os numa espécie de fusão entre as perspectivas ou, nas palavras de Bento Prado: "como uma cobra que se devora a si mesma pelo rabo." (BENTO PRADO, 2017, p. 145).

Então, se faz necessário, principalmente nesse momento de exaltação pseudocientífica e confusões epistemológicas, nos lembrarmos da importância da filosofia, seja pelo retorno a Kant, como nos diz Bento Prado Jr., seja pela via de novos pensadores, para pensar a questão do sujeito e, sobretudo, para refletir sobre como o sujeito pode vir a conhecer.

\section{Referências}

BURKE, P. Origens distantes da globalização. Folha de São Paulo, São Paulo, 11 jul. 2004. +mais!. Disponível em: https://www1.folha.uol.com.br/fsp/mais/fs1107200407. htm. Acesso em: 14. Jul. 2018.

LLINÁS, R. R. I of the Vortex: from neurons to Self. London: MIT Press, 2001.

PRADO JÚNIOR, B. Ipseitas. Belo Horizonte: Autêntica Editora, 2017.

TEIXEIRA, J. F. Mente, cérebro, cognição. Petrópolis: Vozes, 2000.

WITTGENSTEIN, L. Investigações Filosóficas. Tradução: José Carlos Bruni. São Paulo: Editora Nova Cultural, 1999 (Coleção Os Pensadores: Wittgenstein). 